\title{
Mobile Learning in a Rural Medical School: Feasibility and Educational Benefits in Campus and Clinical Settings
}

\author{
Debra Nestel, ${ }^{1,2}$ Katherine Gray, ${ }^{1}$ Andre $\mathrm{Ng},{ }^{1}$ Matthew McGrail, ${ }^{1}$ \\ George Kotsanas, ${ }^{3}$ and Elmer Villanueva ${ }^{1}$ \\ ${ }^{1}$ School of Rural Health, Faculty of Medicine, Nursing \& Health Sciences, Monash University, Northways Road, Churchill, \\ VIC 3842, Australia \\ ${ }^{2}$ HealthPEER, Faculty of Medicine, Nursing \& Health Sciences, Monash University, Wellington Road, Clayton, VIC 3168, Australia \\ ${ }^{3}$ Information Technology, Faculty of Medicine, Nursing \& Health Sciences, Monash University, Wellington Road, Clayton, \\ VIC 3168, Australia
}

Correspondence should be addressed to Debra Nestel; debra.nestel@monash.edu

Received 30 December 2013; Accepted 11 June 2014; Published 29 June 2014

Academic Editor: Chandrashekhar T. Sreeramareddy

Copyright (C) 2014 Debra Nestel et al. This is an open access article distributed under the Creative Commons Attribution License, which permits unrestricted use, distribution, and reproduction in any medium, provided the original work is properly cited.

\begin{abstract}
Students in a new medical school were provided with laptops. This study explored the feasibility and educational benefits of mobile learning for two cohorts of students learning in two settings-university campus (first-year students) and rural clinical placements (second-year students). Evaluation involved questionnaires, focus groups (faculty and students), and document analysis. Descriptive statistics were computed. Focus groups were audio-recorded, transcribed, and analysed thematically. Response rates for questionnaires exceeded $84 \%$. Compared with second-year students, significantly more first-year students (60\%) took their laptops to campus daily $(P=0.14)$ and used their laptops for more hours each day $(P=0.031)$. All students used laptops most frequently to access the internet (85\% and 97\%) and applications (Microsoft Word $(80 \%$ and $61 \%)$ and Microsoft PowerPoint $(80 \%$ and $63 \%)$ ). Focus groups with students revealed appreciation for the laptops but frustration with the initial software image. Focus groups with faculty identified enthusiasm for mobile learning but acknowledged its limitations. Physical infrastructure and information technology support influenced mobile learning. Document analysis revealed significant costs and issues with maintenance. If adequately resourced, mobile learning through university-issued laptops would be feasible and have educational benefits, including equitable access to learning resources, when and where they are needed. However, barriers remain for full implementation.
\end{abstract}

\section{Introduction}

Gippsland Medical School (GMS), Monash University, is a graduate entry medical curriculum offering a bachelor of medicine/bachelor of surgery (MBBS) over four years [1]. GMS is located in rural Victoria, Australia. The curriculum offers very different experiences for students over the first two years with the first predominantly spent on campus while the second is largely spent in rural clinical placements across a large geographical area. GMS provided all students with laptops at the commencement of their studies with students taking a custodial role. The provision of laptops was considered an equitable way in which to provide students with access to resources despite their distribution across significant distances. This educational offering is sometimes referred to as mobile learning. That is, "... the acquisition of any knowledge and skill through using mobile technology, anywhere, anytime, that results in an alteration in behaviour" [2] or "... is any educational provision where the sole or dominant technologies are handheld or palmtop devices." [3] Mobile learning offers highly flexible interactive educational opportunities in which students may synchronously or asynchronously participate in webinars, tutorials, online discussions, wikis, and many other educational activities.

1.1. Mobile Learning in Medical Education. Although the medical and health care literature has examples of mobile 
learning, most focus on a particular element rather than a broad spectrum of activities. Examples usually relate to handheld computers rather than laptops [4]. Most papers described the use of technology in their medical school and few measured the impact of learning. The literature highlighted the feature of mobile learning as bridging distances, creating links, preventing feelings of isolation in students [59], and challenging faculty to develop skills to incorporate and troubleshoot technology on distributed sites and produce e-resources [9-16].

1.2. Mobile Learning Program at GMS. In 2008, we explored first-year students' experiences of mobile learning and found strong support for the initial motive-equitable access to resources [17]. However, there were challenges associated with the laptops themselves, the use of the virtual learning environment (VLE), and the physical settings in which the laptops were used. A limitation of the study was that faculty perspectives were not obtained and that the study only explored students' experiences on campus.

In 2009, 73 first-year students were given Hewlett Packard Elitebook 6930 laptops. Second-year students $(n=60)$ retained Hewlett Packard Compaq 6910p laptops from their first year of medical school. Monash University Studies Online (MUSO) is our university's VLE. It is based on the Blackboard Vista learning management system and allows students and staff to access course information, content, and assessment tasks. "InterLearn" is a supplement to Blackboard and is used by staff for teaching and learning purposes as a collaborative learning tool [18]. Curriculum resources for first- and second-year students are made available to students through MUSO. Students' laptops were provided with a software "image" (i.e., the desktop view) comprising standardised licensed operating system, applications, and utilities. Documentation, including guidelines on acceptable use and student responsibilities, was included in the laptop distribution process. For licensing reasons, the image supplied in 2009 was more restrictive than that offered in 2008. Therefore, the second-year students had prior experience of an image that permitted greater functionality and with which they had expressed satisfaction [17].

In this study we sought to capture student and faculty experiences of mobile learning across two distinctly different rural environments - the campus and hospital-based clinical placements. We posed the following two questions.

(1) To what extent is it feasible to offer mobile learning to medical students on campus and on clinical placements?

(2) What are the educational benefits of mobile learning in these settings?

\section{Methods}

The study questions were addressed using three data collection methods: questionnaires, focus groups, and document analysis.
2.1. Questionnaires. All students were invited to complete questionnaires consisting of 6-point ordinal scales, dichotomous ratings, and free text responses. Questions sought students' satisfaction with the laptops, MUSO, software applications, frequency of laptop use, and the value of online learning resources. The content of the questionnaire was based on an earlier published version [17]. However, our focus in this study was the comparison of mobile learning in different rural learning environments - the campus and clinical placements. Quantitative data was entered into SPSS 17.0 and descriptive statistics computed. Cohort differences were identified using the Mann-Whitney $U$ statistic and Fisher's exact test. Two members of the research team independently analysed free text data for emergent themes.

2.2. Focus Groups. Focus groups are valuable for obtaining a deep understanding of particular issues within a relatively short period of time [19-24]. Focus groups with students were conducted over several months during the academic year to detect changes in experiences and to explore issues from early focus groups. Random and convenience sampling was used to recruit first- and second-year students. The different approaches reflected the small numbers of students at clinical schools.

Academic, clinical, administrative, and technical colleagues were sampled purposively for a separate focus group. Inclusion criteria for the faculty focus group consisted of direct use of technology in some aspect of student learning or support.

Experienced interviewers used topic guides to facilitate focus groups. A template enabled systematic recording of basic information such as participant characteristics, length of focus group, perceived ambience, and quality of responses. Focus groups were audio taped and transcribed by an external agency. Transcripts were deidentified and analysed thematically by two members of the research team.

2.3. Document Analysis. Document analysis is a method used to review textual data [25-29] and we used it to address the question of feasibility of university issued laptops. Formal and informal documents were identified including the technical officer's field notes, curriculum, and purchase documents. Curriculum committee minutes were analysed to track institutional issues with mobile learning.

Monash University Human Research Ethics approval was given for the study.

\section{Results}

3.1. Results-Questionnaires. Response rates to questionnaires were $85 \%(n=62)$ and $84 \%(n=50)$ for first- and second-year students, respectively.

3.2. General Laptop Use. Fifty-one first-year students (82\%) reported prior ownership of a laptop. Thirty-seven first-year students $(60 \%)$ took their laptop to the campus everyday while sixteen (39\%) second-year students took their laptop to the clinical school daily. First-year students (mean $=5.32$, 
TABLE 1: First- and second-year students' reported activities on the laptops.

\begin{tabular}{lccc}
\hline & $\begin{array}{c}\text { First-year students } \\
\text { Laptop activities-No. (\%) }\end{array}$ & $\begin{array}{c}\text { Second-Year students } \\
\text { Laptop activities-No. (\%) }\end{array}$ & $\begin{array}{c}\text { Fisher's exact test } \\
\text { Access to library resources }\end{array}$ \\
Access to the Internet & $54(87 \%)$ & $40(85 \%)$ & $P=0.785$ \\
Email & $60(97 \%)$ & $39(85 \%)$ & $P=0.038^{*}$ \\
Multimedia resources (CDs, books, etc.) & $58(94 \%)$ & $34(72 \%)$ & $P=0.121$ \\
Multimedia from the Internet & $59(95 \%)$ & $35(75 \%)$ & $P=0.002^{* *}$ \\
Preparing presentations & $57(92 \%)$ & $41(87 \%)$ & $P=0.017^{*}$ \\
Word processing & $55(89 \%)$ & $40(85 \%)$ & $P=1.0$ \\
Other & $56(90 \%)$ & $14(30 \%)$ & $P=0.552$ \\
\hline
\end{tabular}

${ }^{*} P<0.05{ }^{* *} P<0.01$.

${ }^{\dagger}$ No. relates to the number of students from each cohort that reported doing each activity.

TABLE 2: First- and second-year students' reported use of applications on laptops.

\begin{tabular}{lccc}
\hline & $\begin{array}{c}\text { First-year students } \\
\text { Application usage-No. (\%) }\end{array}$ & $\begin{array}{c}\text { Second-year students } \\
\text { Application usage-No. (\%) }\end{array}$ & Fisher's exact test \\
\hline Microsoft Word & $50(80 \%)$ & $29(61 \%)$ & $P=0.033^{*}$ \\
Microsoft PowerPoint & $50(80 \%)$ & $30(63 \%)$ & $P=0.079$ \\
Microsoft Excel & $31(50 \%)$ & $20(43 \%)$ & $P=0.561$ \\
Reference Manager & $3(5 \%)$ & $2(4 \%)$ & $P=1.0$ \\
EndNote & $25(40 \%)$ & $15(32 \%)$ & $P=0.425$ \\
Skype & $16(26 \%)$ & $7(15 \%)$ & $P=0.236$ \\
iTunes & $26(42 \%)$ & $25(53 \%)$ & $P=0.235$ \\
Other & $27(44 \%)$ & $15(32 \%)$ & $P=0.239$ \\
\hline
\end{tabular}

${ }^{*} P<0.05$.

${ }^{\dagger}$ No. relates to the number of students from each cohort that reported using each application.

$\mathrm{SD}=3.75)$ reported using their laptops for significantly more hours per day than second-year students (mean $=3.90$, SD $=2.57)(P=0.031)$. Twelve first- $(19 \%)$ and six second-year $(14 \%)$ students reported that they never backed up their work.

3.3. Laptop Activities. Table 1 shows laptop activities reported by students. First-year students most frequently used the laptops for accessing the internet (97\%) and second-year for preparing presentations (87\%). However, all activities were frequently used with $87 \%$ and $72 \%$, the lowest usage rates for first- and second-year students, respectively. First-year students consistently had a higher usage of all laptop activities than second-year students with significant differences in access to the Internet $(P=0.038)$, multimedia resources $(P=0.002)$, and multimedia from the Internet $(P=0.017)$.

3.4. Laptop Applications. Table 2 lists the applications provided to students and shows that Microsoft PowerPoint $(80 \%, 63 \%)$ and Microsoft Word $(80 \%, 61 \%)$ were the most frequently used applications by first- and second-year students, respectively, with statistically significant differences in Microsoft Word usage $(P=0.033)$. Free text comments show the most frequently used additional applications by first-year students were Microsoft Office software (other than PowerPoint and Word) (40\%) and media player software (33\%) while for second-year students they were media player software (60\%) and web browsing programs (41\%). Free text comments also revealed that the most frequently requested applications were Microsoft Office software (other than PowerPoint and Word) (65\%) and instructional or educational multimedia packages (e.g., Anatomedia) (28\%). Students were able to request additional software programs by making a formal application to the information technology office. Only a limited number of programs were made available with many institutional licensing arrangements a major constraint.

3.5. Monash University Studies Online (MUSO). We asked students about MUSO (i.e., the customised VLE) with respect to frequency of use and satisfaction. First-year students reported greater use of nine of twelve MUSO components than second-year students (Figure 1). All differences were significant $(P<0.05)$. Second-year students used quizzes $(P=0.025)$ and formative assessment $(P=0.022)$ more than first-year students. There was no significant difference in use for summative assessment between first- and secondyear students.

Additionally, first-year students were more satisfied with nine of the twelve MUSO items than second-year students $(P<0.05)$ (Figure 2$)$. However, there were no statistically significant differences in satisfaction with quizzes, formative and summative assessments. Mean satisfaction scores for first-year students equalled or exceeded 4 on the 6-point scale 


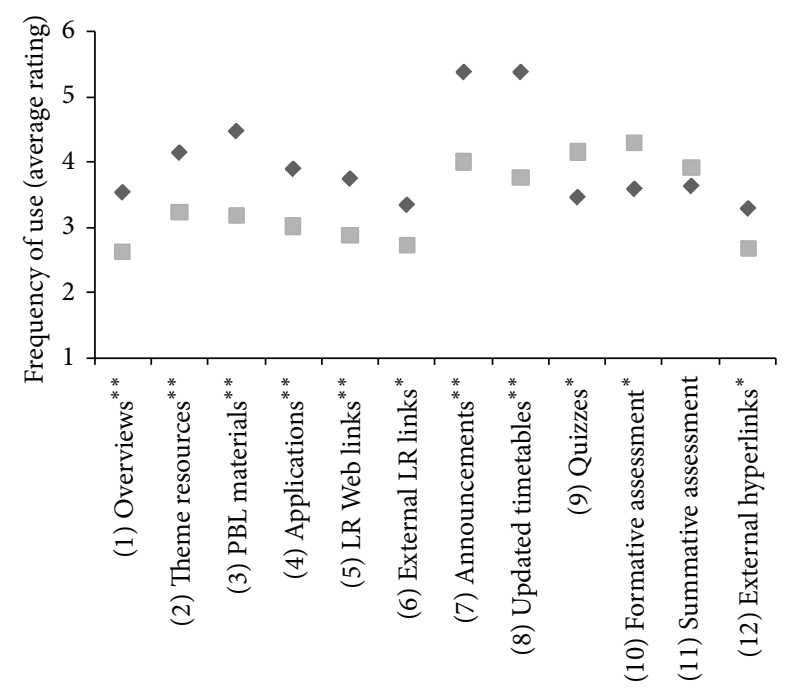

MUSO section

$$
\begin{array}{ll}
\text { 1st year } & { }^{*} P<0.05 \\
\text { 2nd year } & { }^{* *} P<0.01
\end{array}
$$

FIGURE 1: Students' mean scores for frequency of use for various components of MUSO using a rating scale of $1=$ never use, $3=$ occasional use, and $5=$ frequent use.

from 1 (not at all satisfied) to 6 (completely satisfied). In contrast, mean satisfaction scores for second-year students were almost all below 4 .

3.6. Laptop Facets. Using the same scale for satisfaction, students were asked to rate six facets of the laptop and its functionality. For first-year students, mean satisfaction scores exceeded 4 for specifications, learning activities, technical support, MUSO layout, and function (Figure 3). Only satisfaction with applications was below 4 . In contrast, secondyear students' mean score was 4 for specifications with all other ratings being neutral (MUSO layout and function) or dissatisfied (applications, learning activities, and technical support). All differences between first- and second-year students were significant $(P<0.05)$.

3.7. Technical Support. Free text comments showed that firstyear students reported mixed experiences of technical support services. Positive experiences described excellent service from helpful staff. Negative experiences related to a perceived lack of knowledge and interest and slow responses. Secondyear students criticised the university technical support on clinical placements. Main complaints were length of time for repairs, the need for usable software images, suitable applications, and access to wireless internet.

3.8. Results-Focus Groups. Forty-four students participated in six focus groups while six faculty participated in one focus group. Focus groups lasted between 55 and 76 minutes. The ambience of focus groups varied with students and faculty expressing a range of emotions from satisfaction and

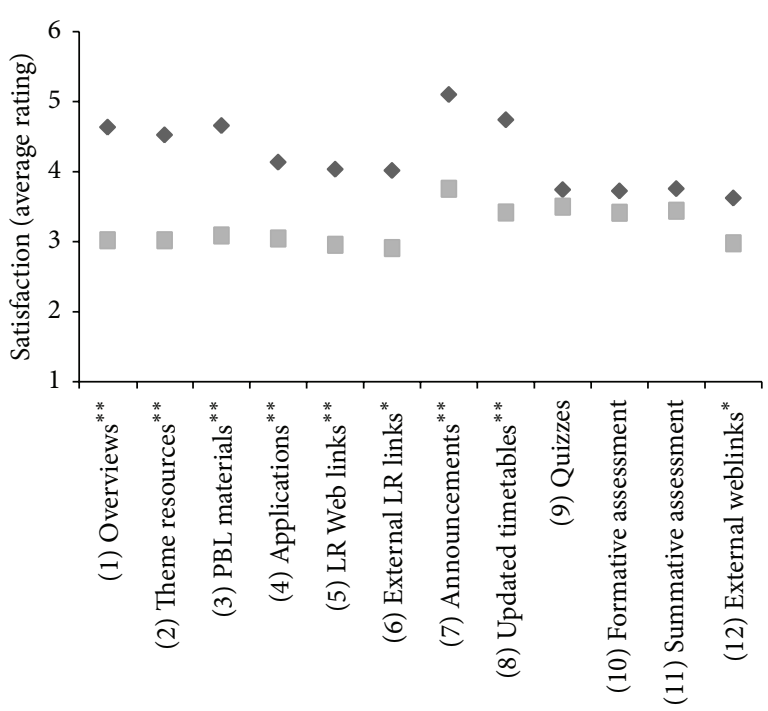

MUSO section

$$
\begin{array}{ll}
\text { 1st year } & { }^{*} P<0.05 \\
\text { 2nd year } & { }^{* *} P<0.01
\end{array}
$$

FIGURE 2: Students' mean scores of satisfaction with various components of MUSO using a rating scale of $1=$ not at all satisfied, $3=$ neutral, and $5=$ completely satisfied.

contentment to frustration, extreme disappointment, and hostility. Responses were thought to be honest although often with initial reticence. Focus groups were conducted over seven months with later focus groups showing higher levels of satisfaction with mobile learning.

3.9. Student Focus Groups. Key themes emerging from student interviews include laptop specifications, benefits, and challenges of mobile learning and MUSO.

3.10. Laptop Specifications. Many students expressed satisfaction with laptop hardware associated with speed, quick start up, intuitiveness, and adequate size. However, some students reported short battery life, problematic software and considered laptops to be too big for lecture theatre desks and for carrying comfortably all day. Students expected usable image supporting Microsoft Office, printer drivers, hard drive access, internet access at GMS, clinical schools, and home, and the option to install personal applications. Students were reluctant to submit laptops to for reimaging because the new software image seemed to restrict laptop functionality. Frustration led to unethical practice for some students- "And we have had to hack the computers to be able to access the internet at times." (FG4).

3.11. Benefits of Mobile Learning. All students appreciated the mobile learning program and considered it generous. However, the provision of laptops also removed personal preferences. First-year students expected that mobile learning would be integral to their whole curriculum while secondyear students acknowledged the increased importance of 


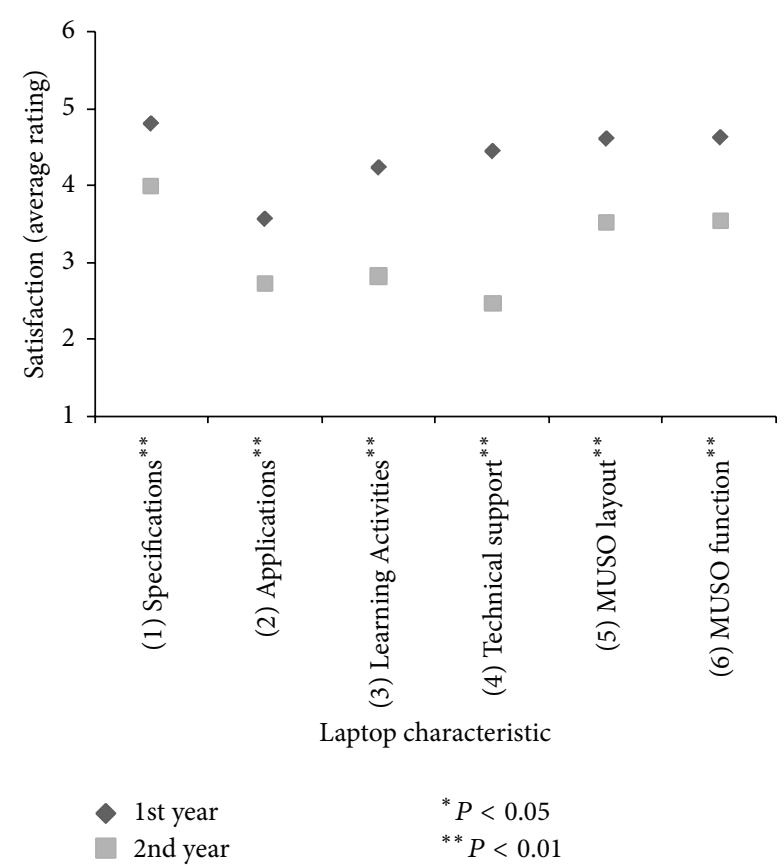

FIGURE 3: Students' mean ratings of satisfaction with various components of mobile learning using a rating scale of $1=$ not at all satisfied, 3 = neutral, and $5=$ completely satisfied.

learning from patients and clinicians. However, they continued to value access to their personal documents and broader curriculum resources on laptops. First-year students reported benefits of mobile learning that enhanced their learning such as internet access, portability, range of applications, access to curriculum materials, personalised study notes, and efficiencies in sharing information with colleagues. They reported that mobile learning assisted problem based learning (PBL) sessions particularly in preparing and presenting reports to their PBL group.

\section{"Take more notes, faster. Ease of email and sharing of information, ease of presentations," (FG1).}

Second-year students reported fewer benefits of mobile learning noting the value of immediate information exchange, saving on printing and paper, and ability to personalise lecture notes and write up PBL notes.

3.12. Challenges of Mobile Learning. There were differences in the challenges of mobile learning reported by first- and second-year students. First-year students found the following aspects of mobile learning challenging-the initial laptop distribution process (timing), the physical specifications of laptops, and "appropriate" use during classes. Students reported mixed messages from faculty with regard to mobile learning. For example, some faculty asked students to put their laptops away during sessions. Students reported difficulties using laptops in lectures due to small fixed desks, inadequate battery life and too few power sockets, and limited wireless connectivity.
Second-year students reported disappointment and frustration with communication of information from faculty on the management of laptops, particularly relating to the reimaging of laptops in the first semester. That is, the need to return laptops to the university IT department for refreshing of applications.

"There's essentially been no form of communication from the university about the problem, what would we be expecting and it's eventuated in us getting a lot less than what we were actually told that we were getting for this year." (FG5).

This was an overriding issue for much of the first semester. The geographic dispersion of students in clinical sites was thought to have compounded the problems. Additionally, students reported site-specific issues with limited access to the internet due to firewalls and other security measures. Facilities at clinical sites varied widely. Students reported compromised learning environments with building works in progress that would likely lead to high quality facilities.

3.13. Monash University Studies Online (MUSO). Most students commented on the layout and organisation of MUSO and some expressed frustration with navigation. First-year students wanted timely posting of lectures, guidelines on assignments, and results updated. Students appreciated that "MUSO prevented their email being clogged up with messages on new postings" (FG4) but also wanted some way of knowing when notices had been uploaded. Second-year students valued MUSO and saw it as a helpful tool, offering good curriculum support materials and specific programs for discipline-specific topics (e.g., pathology). MUSO usage varied between clinical placement sites. Clinical placements with few students $(<10)$ relied on personal exchanges while clinical placements with more students $(>10)$ continued to use MUSO for some faculty-student communication. Students at smaller sites who had become used to personal communication channels often overlooked notices from campus.

3.14. Faculty Focus Groups. Key themes that emerged from the faculty focus group were the impact of laptop use, MUSO, and electronic learning resources. Faculty made no distinction in mobile learning between campus and clinical school.

3.15. Laptop Use. Overall, faculty considered the mobile learning program valuable. However, some faculty reported "inappropriate use" of laptops and thought they impeded communication, creating "physical" and "social" barriers between students and the lecturer/s. Most faculty viewed laptops positively with respect to PBL. Faculty noted insufficient wireless capacity in lecture theatres and made suggestions for increasing the use of additional technologies that have advantages for teachers and students. Faculty noted student frustration with the delay in providing a fully usable image.

3.16. Monash University Studies Online (MUSO). Faculty valued MUSO as a good faculty-student communication tool. 
Some faculty provided lecture slides and other material on MUSO. Faculty commented on the layout and organisation of MUSO and recommended using more hyperlinks. Faculty considered MUSO to have improved from the previous year. Administrators in the second-year program reported that they did not use MUSO since they saw most students in person on a daily basis. They also indicated that new facilities that were being built would likely improve mobile learning.

3.17. Electronic Learning Resources. Few teachers reported modification or development of teaching methods or materials. One teacher had written new materials in ToolBook software. Faculty wanted professional activities to support them in creating and using electronic learning resources.

\begin{abstract}
"I specifically developed ToolBook applications for every lecture I was giving, ... and I specifically requested that my laptop be a student laptop so that I knew, was guaranteed that all my applications developed in that environment would work in their environment." (FG7).
\end{abstract}

3.18. Results-Document Analysis. Purchase documents report the cost of purchase as $\$ 132,616$ (2009) with warranty costs for three years of $\$ 21,000$. For second-year students (2008), there was a purchase cost of $\$ 72,960$ and warranty cost for three years of $\$ 17,100$. Funding formed part of the overall GMS budget. Analysis of field notes and meeting minutes revealed problems in the implementation process of mobile learning such as delays in laptop distribution, delays in reimaging of laptops, software problems with the new image, and no or minimal wireless capacity at clinical sites. Many of these problems were resolved over the course of the academic year. Curriculum committee minutes tracked the building progress of new learning environments at some clinical placement sites.

\section{Discussion}

Despite numerous problems, mobile learning on campus and clinical sites proved feasible. Overall, most students and faculty valued mobile learning. To some extent, the university issued laptops provided an equitable basis for students to participate in their curriculum. However, it removed student choice in hardware and was compromised by physical infrastructure. Second-year students used their laptops less than their first-year counterparts and were also less satisfied with mobile learning. This may reflect the changed emphasis of their curriculum where they are expected to spend significant amounts of time in clinical settings. Several site-specific issues impacted the quality of mobile learning in clinical settings.

The greatest educational benefit of the laptops was providing students with access to educational materials (assuming internet access). Additionally, a significant benefit was the opportunity to self-manage learning resources. Mobile learning enhanced the quality of PBL sessions (in small groups). The results of the three methods-questionnaires, focus groups, and document analysis-were largely consistent.
Findings from the literature on mobile learning as bridging distances were not consistently borne out in this study. The second-year cohort often had limited internet access and adopted local approaches to faculty-student and studentstudent communication or relied on other personal devices (e.g., mobile phones) rather than laptops.

Cohort differences in mobile learning reflect the diverse educational experiences offered to students. That is, first-year students are based on campus. They are able to use their laptop in PBL sessions and lectures with access to MUSO when needed. In contrast, second-year students are in clinical placements where they encountered hospital firewalls, preventing internet access. Alternative and more portable mobile devices may better support student learning in these distributed clinical placements. However, the improved program of physical infrastructure developments across clinical placements is likely to advance mobile learning. Second-year students requiring information technology services usually needed to return to GMS which was impracticable and inconvenient. Like first-year students, the second-year students also had substantial learning in small groups, but unlike their junior counterparts, they had very few lectures. In many respects, faculty did not offer learning activities that leveraged the potential benefits of mobile learning.

Many students do not back up their work. Students need further guidance and support in terms of process and/or providing resources (e.g., increased memory capacity, external drives). Despite instruction in backup processes since the first study, improvements were not evidenced in reported student behaviour. Of concern was the unethical practice of students breaching licensed software contractual arrangements. Although driven by frustration (restrictive software image) breaches of professional codes of practice are unacceptable.

Several challenges related to the mobile learning program. Students were mainly satisfied with the hardware but not the software. The different laptops issued to firstand second-year students may have accounted for some of the differences in satisfaction, but the laptops were similar. Further, the second-year cohort who was surveyed in 2008 when they were first-year students were much more satisfied with their laptops. Simply by being a year older and with the added limitation of a restricted image in 2009 may have led to greater dissatisfaction.

The design of teaching and learning spaces needs consideration to better support mobile learning. Facilities on campus were well designed for small group sessions. However, the location and number of sockets, desk and chair heights in lecture theatres did not facilitate laptop use.

Although making suggestions for improvement, MUSO was considered valuable for learning. Compared with firstyear students, MUSO was not well used by second-year students or faculty. For students, this was related to the absence of wireless connectivity and that daily use was no longer expected. Faculty do not rely on regular use of MUSO for teaching although there are some defined learning activities for first- and second-year students. MUSO offers a forum for quizzes and other tests benefiting students. This was especially important for second-year students dispersed 
across the region. However, the facility was not well utilised. Mobile learning provided second-year students with a means of keeping in touch with their professional learning community when it was required.

In line with reported mobile learning literature, our faculty will need to support development of mobile learning specific resources. Very few materials were developed for mobile learning with paper-based materials simply being made available electronically. Although appreciated by students, it does not tap the potential of mobile learning. Some faculty wanted guidance on ways to present their teaching materials to students and would like to develop new skills to create materials for mobile learning. Minimal use was made of wikis, blogs, and other technologies, which could facilitate improvements in mobile learning. Although many students used these features of mobile learning, they chose options outside the curriculum.

The literature describes examples of skills-based activities for mobile learning. GMS has the potential to strengthen these activities especially for teaching and learning clinical skills.

Study Limitations. There are a number of limitations to the study. The study is located in just one medical school. Response rates in the questionnaires were satisfactory and likely to be representative of the cohorts but instruments relied on self-report, which may be unreliable. The different sampling frames for focus groups may have influenced the quality of responses. Faculty at clinical placement sites were underrepresented. In the process of document analysis we may have inadvertently excluded some critical materials. We did not record demographic data of faculty or students.

Although the study is located within a rural-based medical school, the findings are likely to have relevance for other programs in which students undertake clinical placements away from campus.

Future research is needed to aid the support of faculty members not only in their use of electronic learning resources, but also in the creation and development of new electronic learning resources.

\section{Conclusions}

The provision of laptops went some way to providing equitable access to curriculum resources. Within the prevailing economic climate, the provision of university issued laptops with a customised VLE was appreciated but not necessarily significantly advancing either communication or learning. Further, the provision of laptops reduced the variety of devices which students used to engage with mobile learning. Although some of our results complement existing literature, the study differs by offering more detail than most published in the medical education literature. Our study also related to the entire curriculum and not just one component. Further, our students seemed to experience higher levels of frustration in relation to the software image than those reported in other studies.

\section{Conflict of Interests}

The authors declare that there is no conflict of interests regarding the publication of this paper.

\section{Acknowledgments}

This project was funded by the Faculty of Medicine, Nursing and Health Sciences Teaching and Learning Performance Fund, Project Grants Scheme.

\section{References}

[1] Gippsland Medical School, http://www.med.monash.edu.au/ medical/gippsland/.

[2] S. J. Geddes, "Mobile learning in the 21st century: benefit for learners," Knowledge Tree e-journal, vol. 30, no. 3, pp. 214-228, 2004.

[3] J. Traxler, "Defining mobile learning," in Mobile Learning 2005, P. Isaias, C. Borg, P. Kommers, and P. Bonanno, Eds., International Association for development of the Information Society Press, Valletta, Malta, 2005.

[4] D. Nestel, H. Brenton, and R. Kneebone, "Handheld computers in veterinary medical education: a view from human medical education," Journal of Veterinary Medical Education, vol. 32, no. 1, pp. 121-126, 2005.

[5] D. Seabra, M. Srougi, R. Baptista, L. J. Nesrallah, V. Ortiz, and D. Sigulem, "Computer aided learning versus standard lecture for undergraduate education in urology," Journal of Urology, vol. 171, no. 3, pp. 1220-1222, 2004.

[6] G. Yamey, "The professor of "telepreventive medicine"," British Medical Journal, vol. 328, no. 7449, article 1158, 2004.

[7] P. W. Callas, T. F. Bertsch, M. P. Caputo, B. S. Flynn, S. Doheny-Farina, and M. A. Ricci, "Medical student evaluations of lectures attended in person or from rural sites via interactive videoconferencing," Teaching and Learning in Medicine, vol. 16, no. 1, pp. 46-50, 2004.

[8] D. J. Solomon, G. S. Ferenchick, H. S. Laird-Fick, and K. Kavanaugh, "A randomized trial comparing digital and live lecture formats ISRCTN40455708," BMC Medical Education, vol. 4, article 27, 2004.

[9] S. C. Stain, M. Mitchell, R. Belue et al., "Objective assessment of videoconferenced lectures in a surgical clerkship," American Journal of Surgery, vol. 189, no. 1, pp. 81-84, 2005.

[10] D. M. Fleiszer, N. H. Posel, and S. P. Steacy, "New directions in medical e-curricula and the use of digital repositories," Academic Medicine, vol. 79, no. 3, pp. 229-235, 2004.

[11] L. Howatson-Jones, "Designing web-based education courses for nurses," Nursing standard, vol. 19, no. 11, pp. 41-44, 2004.

[12] G. W. Matkin, "Distance education: its concepts and constructs," Journal of Veterinary Medical Education, vol. 34, no. 3, pp. 220225, 2007.

[13] J. B. McGee and M. Begg, "What medical educators need to know about 'Web 2.0"' Medical Teacher, vol. 30, no. 2, pp. 164169, 2008.

[14] J. G. Ruiz, M. J. Mintzer, and R. M. Leipzig, "The impact of elearning in medical education," Academic Medicine: Journal of the Association of American Medical Colleges, vol. 81, no. 3, pp. 207-212, 2006. 
[15] J. M. Sargeant, "Medical education for rural areas: opportunities and challenges for information and communications technologies," Journal of Postgraduate Medicine, vol. 51, no. 4, pp. 301-307, 2005.

[16] M. H. Sims, N. Howell, and B. Harbison, "Videoconferencing in a veterinary curriculum," Journal of Veterinary Medical Education, vol. 34, no. 3, pp. 299-310, 2007.

[17] D. Nestel, A. Ng, K. Gray et al., "Evaluation of mobile learning: students' experiences in a new rural-based medical school," BMC Medical Education, vol. 10, no. 1, article 57, 2010.

[18] C. Varsavsky, W. McKenzie, G. Romeo, and L. Webster, InterLearn-A Tool for Collaborative Learning, Ascilite, Auckland, New Zealand, 2002.

[19] R. S. Barbour, "Making sense of focus groups," Medical Education, vol. 39, no. 7, pp. 742-750, 2005.

[20] J. Kitzinger, "The methodology of focus groups: the importance of interaction between research participants," Sociology of Health \& Illness, vol. 16, no. 1, pp. 103-121, 1994.

[21] J. Kitzinger, "Focus groups," in Qualitative Research in Health Care, C. Pope and N. Mays, Eds., pp. 21-31, BMJ, Oxford, UK, 2006.

[22] D. Morgan, "Focus groups," Annual Review of Sociology, vol. 22, pp. 129-152, 1996.

[23] D. L. Morgan, Focus Groups as Qualitative Research, SAGE, Thousand Oaks, Calif, USA, 2nd edition, 1997.

[24] D. Mertens, Research and Evaluation in Education and Psychology: Integrating Diversity with Quantitative, Qualitative, and Mixed Methods, Sage Publications, Thousand Oaks, Calif, USA, 2005.

[25] K. Garman, "Eastside, westside... an exercise in applying document analysis techniques in educational evaluation," Research on Evaluation Program Paper and Report Series 78, Northwest Regional Educational Lab, 1982.

[26] S. Merriam, Qualitative Research and Case Study Applications in Education, Jossey-Bass, San Francisco, Calif, USA, 1977.

[27] L. Prior, Using Documents in Social Research, Sage, London, UK, 2003.

[28] J. Scott, Documentary Research, Sage, London, UK, 2006.

[29] M. Patton, Qualitative Research Evaluation Methods, Sage, Thousand Oaks, Calif, USA, 3rd edition, 2002. 

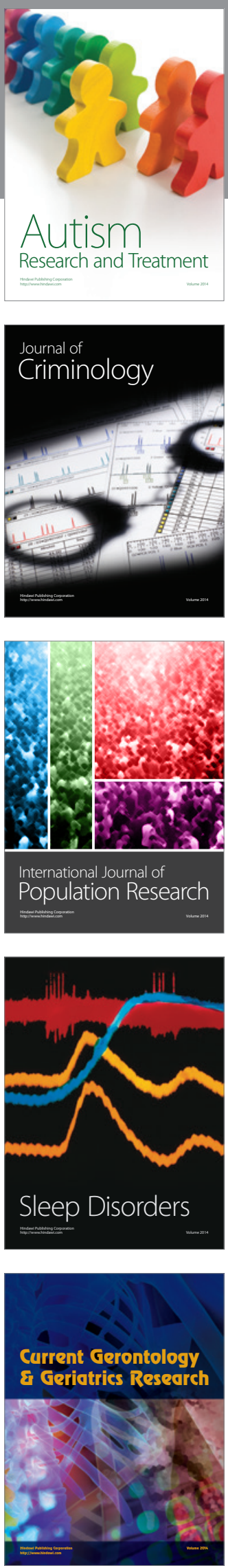
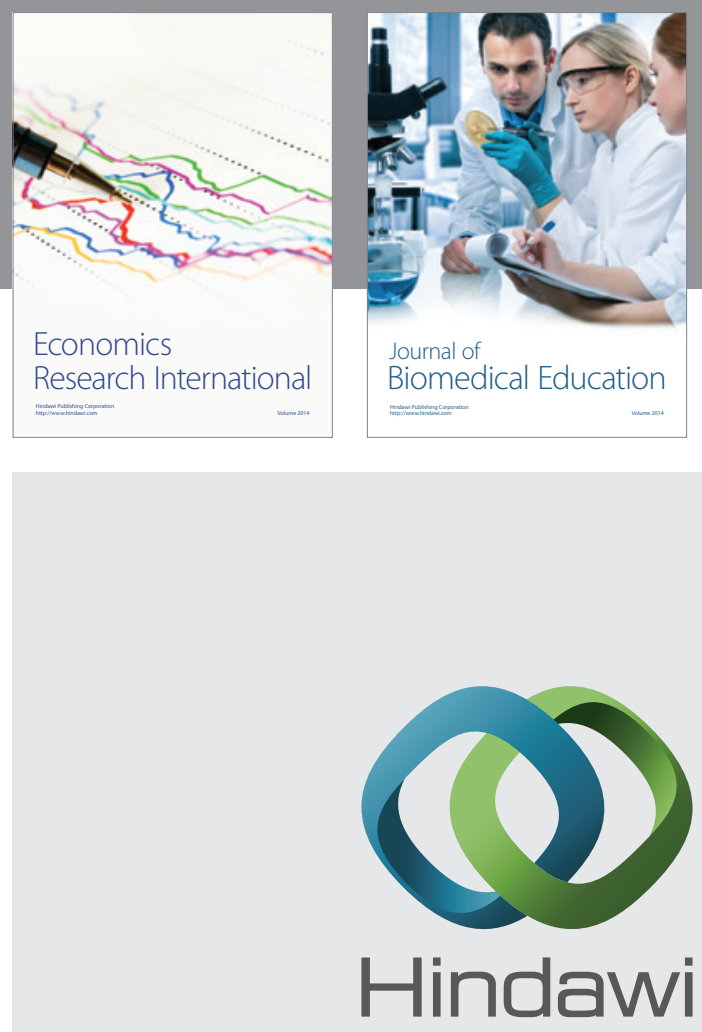

Submit your manuscripts at

http://www.hindawi.com
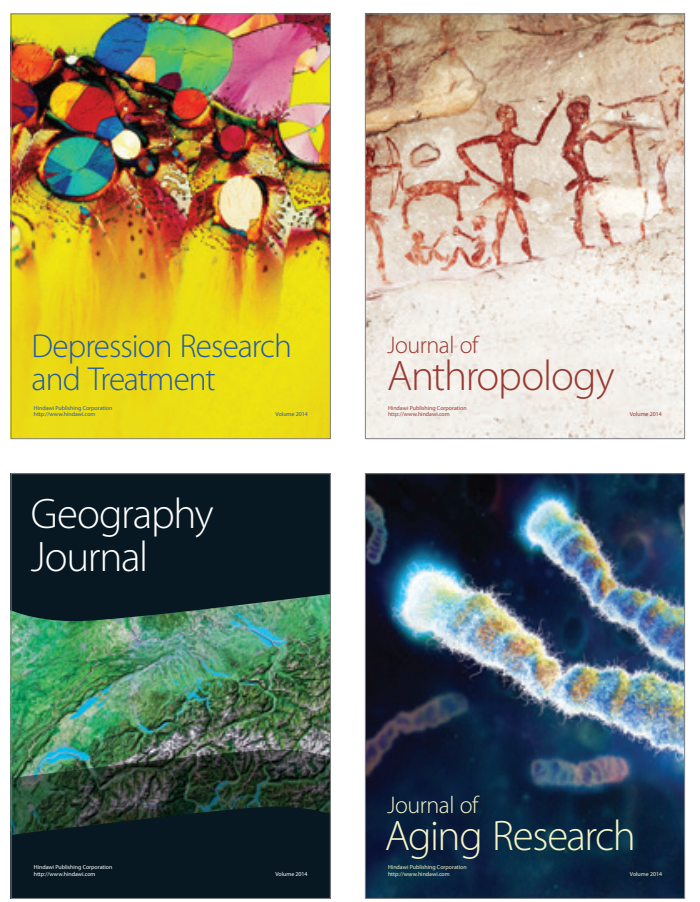
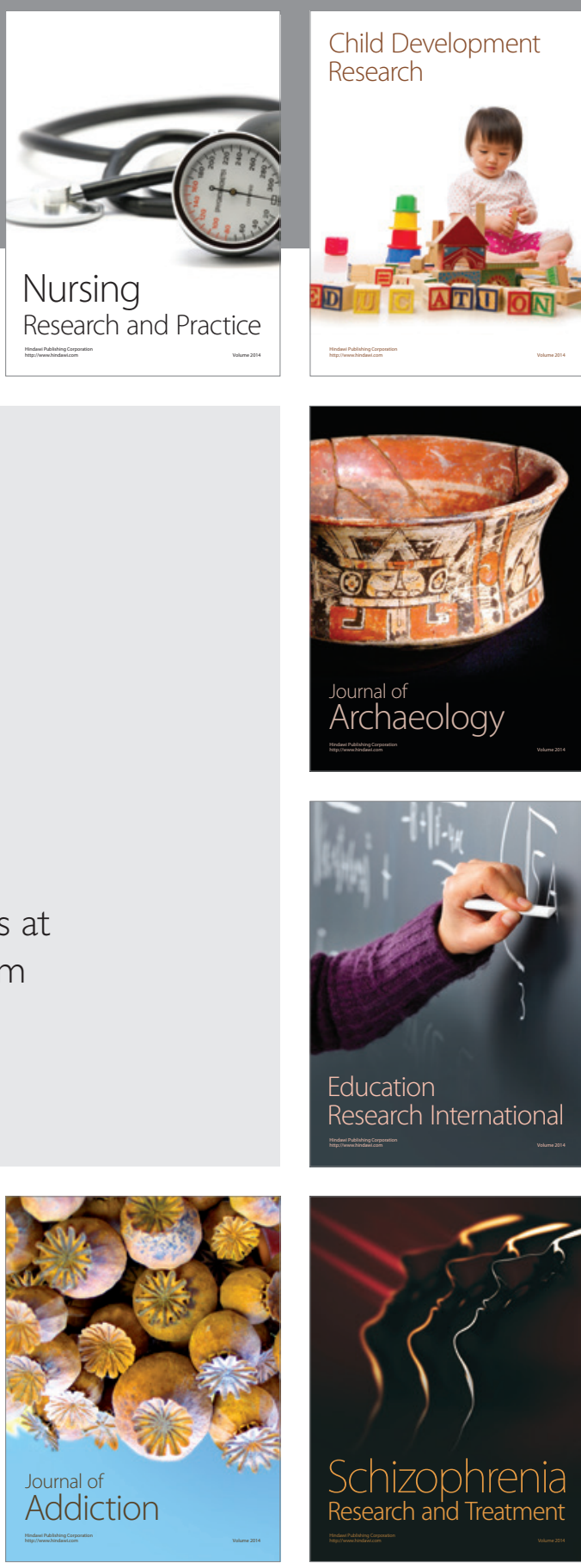

(D)
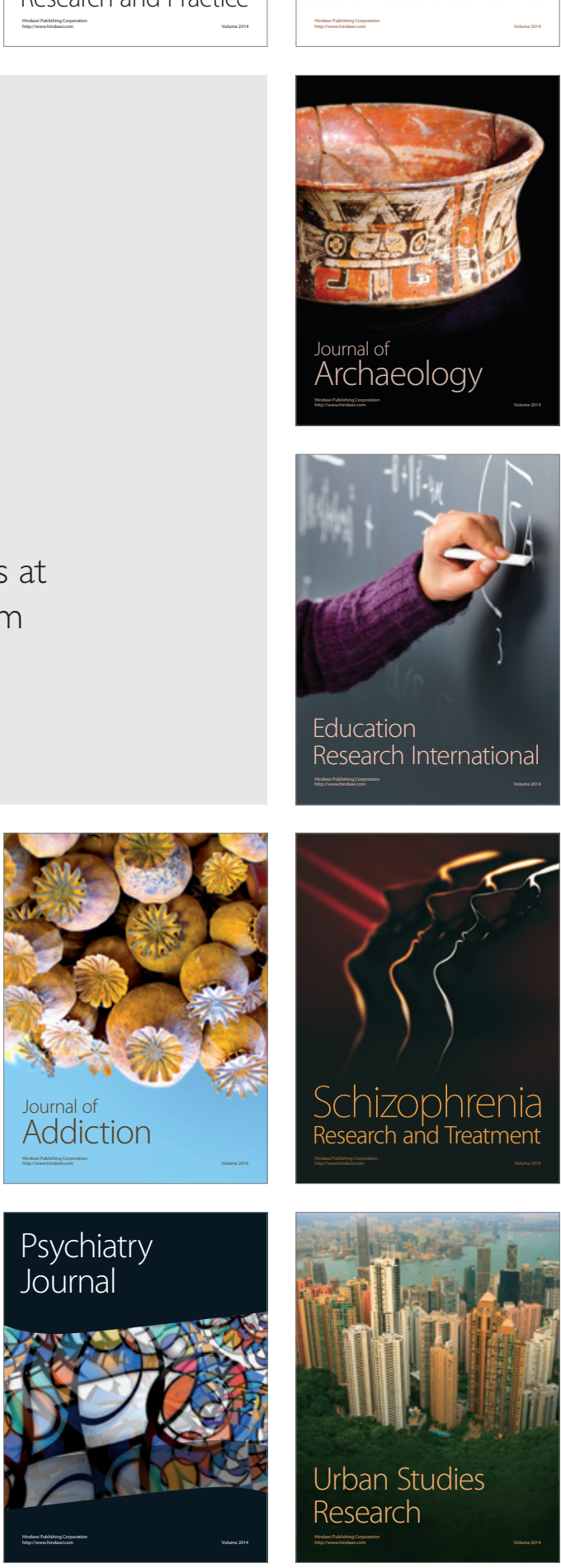